\title{
Array Mutual Coupling Reduction Using L-Loading E-Shaped Electromagnetic Band Gap Structures
}

\author{
Tao Jiang, Tianqi Jiao, and Yingsong Li \\ College of Information and Communications Engineering, Harbin Engineering University, Harbin 150001, China \\ Correspondence should be addressed to Yingsong Li; liyingsong@ieee.org
}

Received 19 May 2016; Revised 8 July 2016; Accepted 13 July 2016

Academic Editor: Elena De Cos

Copyright (C) 2016 Tao Jiang et al. This is an open access article distributed under the Creative Commons Attribution License, which permits unrestricted use, distribution, and reproduction in any medium, provided the original work is properly cited.

\begin{abstract}
A mutual coupling reduction method between microstrip antenna array elements is proposed by using periodic L-loading Eshaped electromagnetic band gap structures. Two identical microstrip patch antennas at $2.55 \mathrm{GHz}$ are settled together and used to analyze the performance of the designed two-element antenna array. The two antenna elements are settled with a distance of about $0.26 \lambda$. To reduce the mutual coupling, the L-loading E-shaped electromagnetic band gap structures are used between these antenna elements. The simulated and measured results show that the isolation of the antenna array reaches $38 \mathrm{~dB}$, which has a mutual coupling reduction of $26 \mathrm{~dB}$ in comparison with the antenna array without the decoupling structures.
\end{abstract}

\section{Introduction}

Microstrip antenna and its array are very popular in wireless communication systems in recent decades. Moreover, with the demand of large scale antenna arrays and small size, the mutual coupling reduction between the antenna array elements becomes more serious. Therefore, the technique to reduce the coupling is more urgent to be boosted. There are many techniques that are effective in reducing mutual coupling in which three solutions are prominent. The first categorization is to add parasitic elements on each patch antenna, which can achieve a $21 \mathrm{~dB}$ mutual coupling reduction between the antenna array elements in the bandwidth of $2.2 \%[1,2]$. The second group is to put various defected ground structures on the ground to improve the isolation [3-5]. As a result, a mutual coupling has been reduced to about $15 \mathrm{~dB}$ with only one defected ground structure. The third solution is to use unique band-stop structure to reduce the mutual coupling of coplanar antenna array such as electromagnetic band gap (EBG) structures. After that, various EBG structures have been put between the two antenna elements to reduce the coupling, including two EBG cells [6-11]. However, these EBG structures may change the center frequency of the antenna resonances.

From the three solutions discussed above, the EBG structures are very popular and have been widely adopted to give a coupling reduction in antenna array design [12-15]. There are two typical methods to carry out an antenna array. However, these coupling structures depend on whether the EBG structures and the antenna array are in the same plane or not [16]. If the EBG structure and the patch antenna array are not in the same plane, a multilayer EBG [16-18] structure composed of high and low permittivity layers is utilized.

In this paper, a mutual coupling reduction method between microstrip antenna array elements is proposed by using periodic L-loading E-shaped EBG structures. The proposed EBGs are settled between the two antenna elements and are placed in the same plane with the two antenna elements. By using the proposed EBG structures, more than $26 \mathrm{~dB}$ mutual coupling reduction is achieved without affecting the radiation patterns on the proposed antenna array.

\section{Initial Design}

This paper presents periodic L-loading E-shaped electromagnetic band gap structure to reduce the mutual coupling between two identical microstrip antenna elements. The proposed periodic L-loading E-shaped EBG is installed on the same plane and set between the two antenna elements. A mutual coupling reduction of $26 \mathrm{~dB}$ has been achieved on 


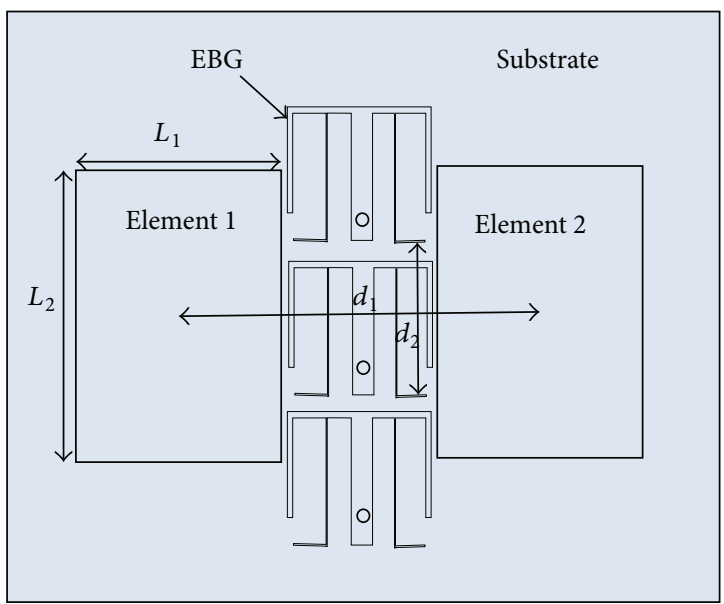

(a) Antenna array with proposed L-loading E-shaped EBG structure

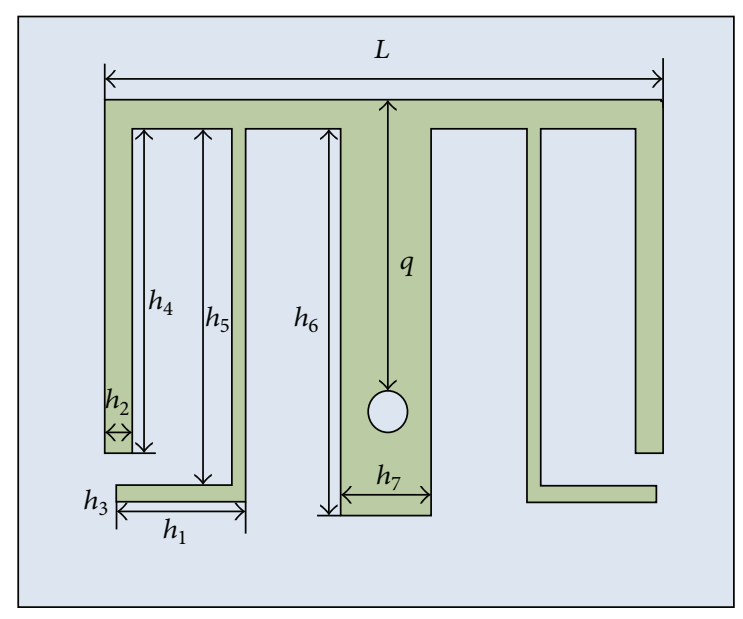

(b) Proposed L-loading E-shaped EBG cell

FIGURE 1: Antenna array and the proposed L-loading E-shaped EBG decoupling structure.

the basis of the proposed EBG structure which has slight effects on the radiation patterns of the proposed two-element antenna array.

2.1. EBG Structure. The configuration of the proposed EBG structure is shown in Figure 1. The two antennas are identical and are designed to operate at the center frequency of $2.55 \mathrm{GHz}$. The proposed two-element antenna array is printed on a substrate whose permittivity is 4.4 . The thickness of the substrate is $1.6 \mathrm{~mm}$, which is very popular in practical engineering applications [19-21]. The antenna array is optimized based on HFSS which is a finite element method. The antenna is optimized to a size of $56 \times 60 \mathrm{~mm}^{2}$, including the entire ground plane. In this design, the antenna element is a rectangle patch antenna fed by a probe and the optimal dimensions are $L_{1}=15 \mathrm{~mm}$ and $W_{1}=28 \mathrm{~mm}$. In order to reduce the coupling between these two antennas, a periodic L-loading E-shaped EBG structure is integrated together with the antenna array. The periodic L-loading E-shaped EBG structure consists of three EBG cells and the distance between the adjacent EBGs is $d_{2}=18.7 \mathrm{~mm}$. The two antenna elements are separated by a distance of $30 \mathrm{~mm}$. The dimensions of the proposed EBG cell are shown in Figure 1(b). The antenna coupling can be reduced by controlling the dimensions of the proposed EBG structure. The dispersion diagram of the proposed EBG is shown in Figure 2. It can be seen that the gray area indicates the complete stopband in which no wave propagates in any directions. Thus, we can use the proposed EBG structure to reduce the coupling between the two antenna elements.

\subsection{Non-L-Loading E-Shaped EBG Structure. From the} design of EBG cell, we can see that our EBG cell is comprised of an L-stub and an E-shaped strip. The EBG cell is shorted to the ground plane via a hole [22-25]. We use three EBG cells to design the coupling structure and they are assigned periodically in the centerline between the array elements. The mutual coupling is evaluated by using $S_{12}$. Since the antenna array is symmetrical, we use $S_{11}$ and $S_{12}$ to discuss the performance of the proposed antenna. First, proposed EBG structure without L-loading is settled between these two antennas and the array is shown in Figure 3. Mutual coupling is investigated by the HFSS and the simulation results are shown in Figure 4. It can be seen that the proposed antenna with EBG and without EBG has nearly the same resonance frequency. Moreover, the proposed EBG structure makes the resonance frequency higher. Our proposed EBG structure effectively reduces the coupling of the antenna array. As a result, $10 \mathrm{~dB}$ coupling has been reduced. Thus, we can say that the EBG is useful to improve the isolation between the antenna elements.

The radiation patterns of the proposed antenna array with non-L-loading EBG structure are shown in Figure 5. It is found that the proposed has good unidirectional radiation patterns and the proposed non-L-loading EBG structure has a little effect.

2.3. L-Loading E-Shaped EBG Structure. Based on the analysis mentioned above, we find that the proposed EBG structure is effective in reducing the mutual coupling. Next, two Lshaped stubs are integrated into the E-shaped EBG to form L-loading E-shaped EBG structure. Then, the L-loading Eshaped EBG structure is utilized to reduce the mutual coupling of the antenna array, which is the antenna array shown in Figure 1. Also, the performance of the proposed antenna array is evaluated by the HFSS and the results are shown in Figure 6. We can see that the EBG structure with and without L-loading has no effect on the resonance frequency of the proposed antenna array. However, the mutual coupling is reduced to about $10 \mathrm{~dB}$.

To understand the principle of the decoupling, the current distributions of the antenna array are given in Figure 7. We can see that the current is effectively stopped by using the L-loading E-shaped EBG structure. In the proposed antenna array with L-loading E-shaped EBG structure, the current is mainly flowing on the left antenna element and the L-loading 


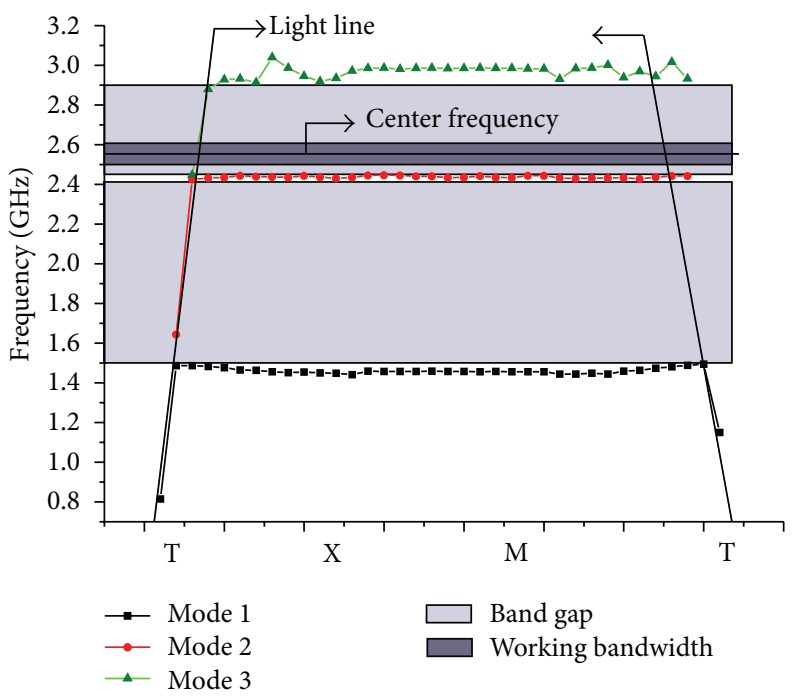

Figure 2: Dispersion diagram of the proposed EBG.

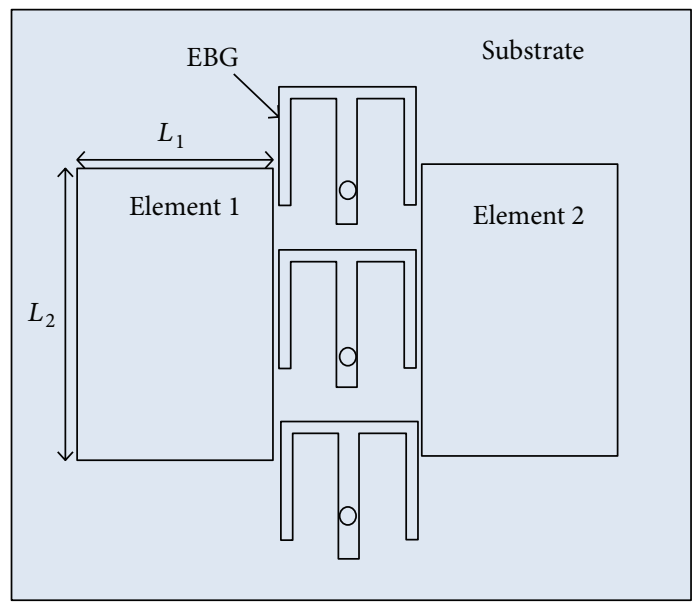

FIgURE 3: Antenna array with non-L-loading E-shaped EBG structure.

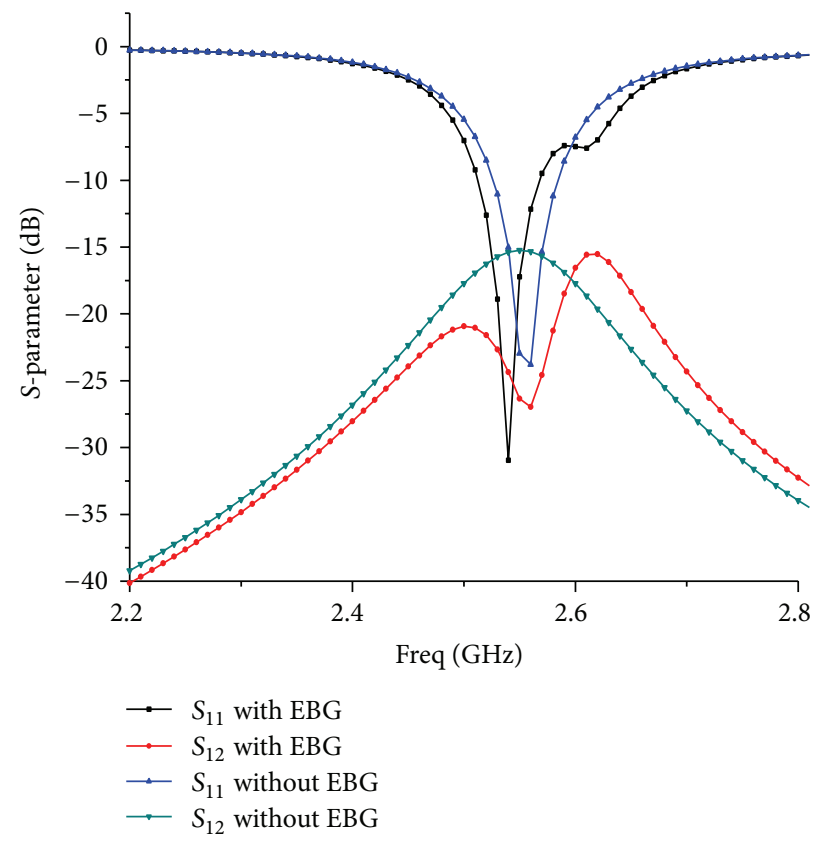

FIGURE 4: S-parameter of the proposed antenna array with non-L-loading EBG structure. 


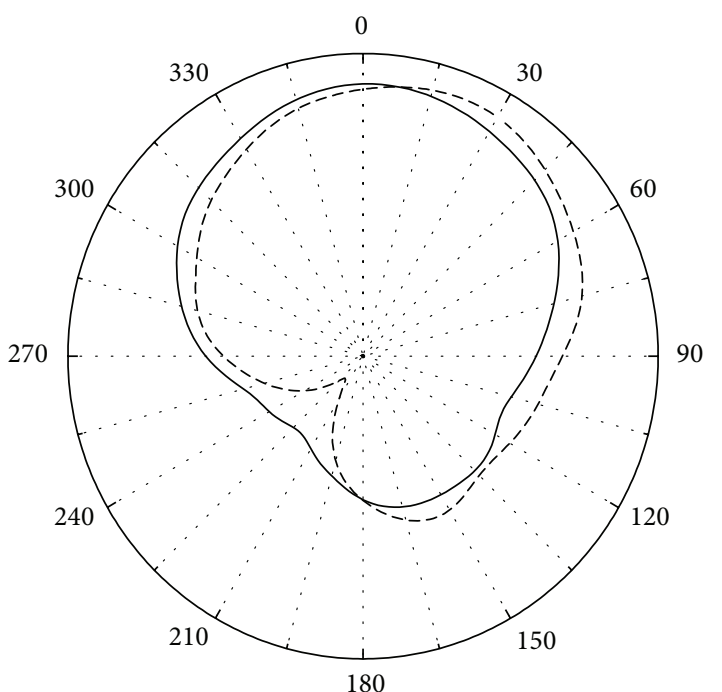

- $H$-plane without EBG

-- $H$-plane with EBG

(a)

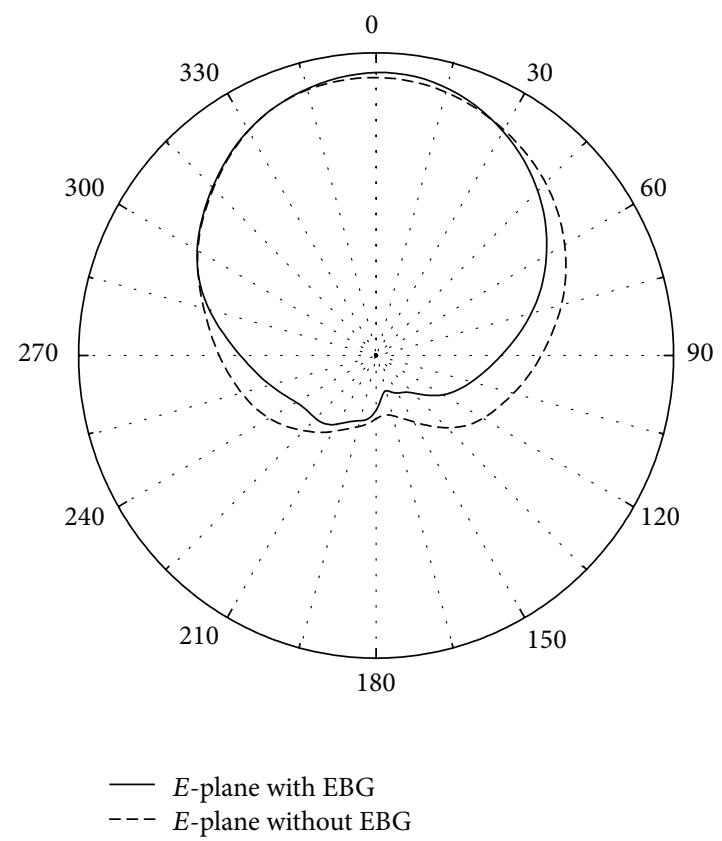

(b)

FIGURE 5: Radiation patterns of the antenna array with non-L-loading EBG structure. (a) $H$-plane. (b) E-plane.

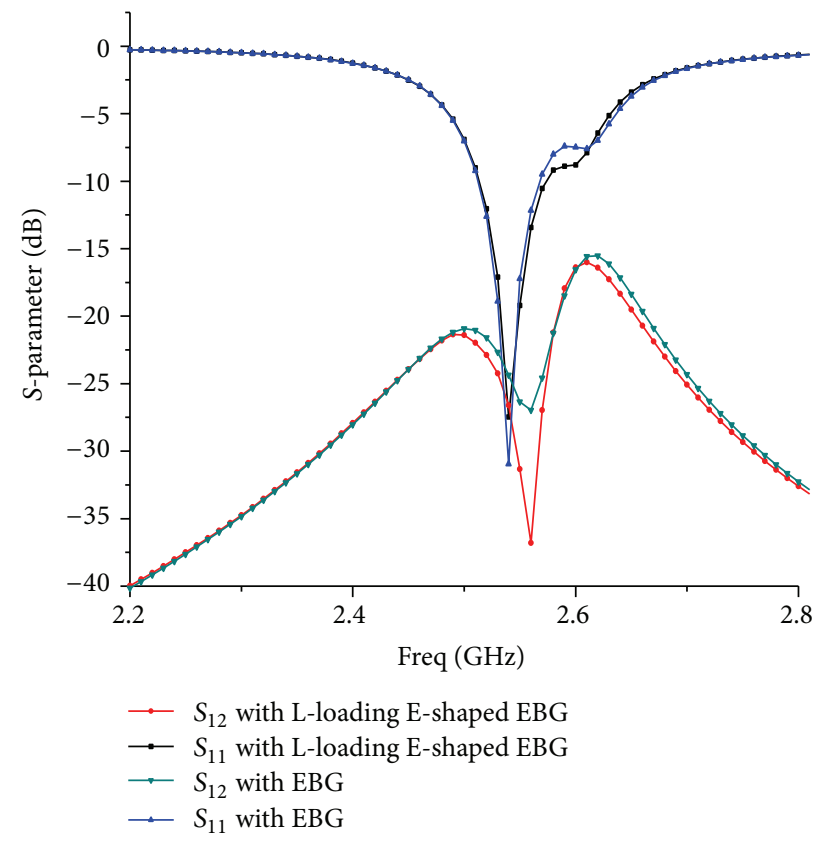

Figure 6: Antenna array with designed L-loading E-shaped EBG structure.

E-shaped EBG structure. The current on the right antenna is small. This is because the L-loading E-shaped EBG structure effectively prevents the current from the left antenna to the right antenna. As for the antenna array without the L-loading E-shaped EBG structure, both the left and the right antenna elements have obvious current distribution because they share the common ground plane. Thus, we can see that the proposed L-loading E-shaped EBG structure can reduce the current effect on the adjacent antenna elements and hence it can improve the decoupling between the adjacent antenna elements. The radiation patterns of the proposed antenna are shown in Figure 8, which are similar to the antenna array without L-loading E-shaped EBG structure. It is clear to see that the L-loading E-shaped EBG structure has little effects on the radiation patterns of the antenna array. 

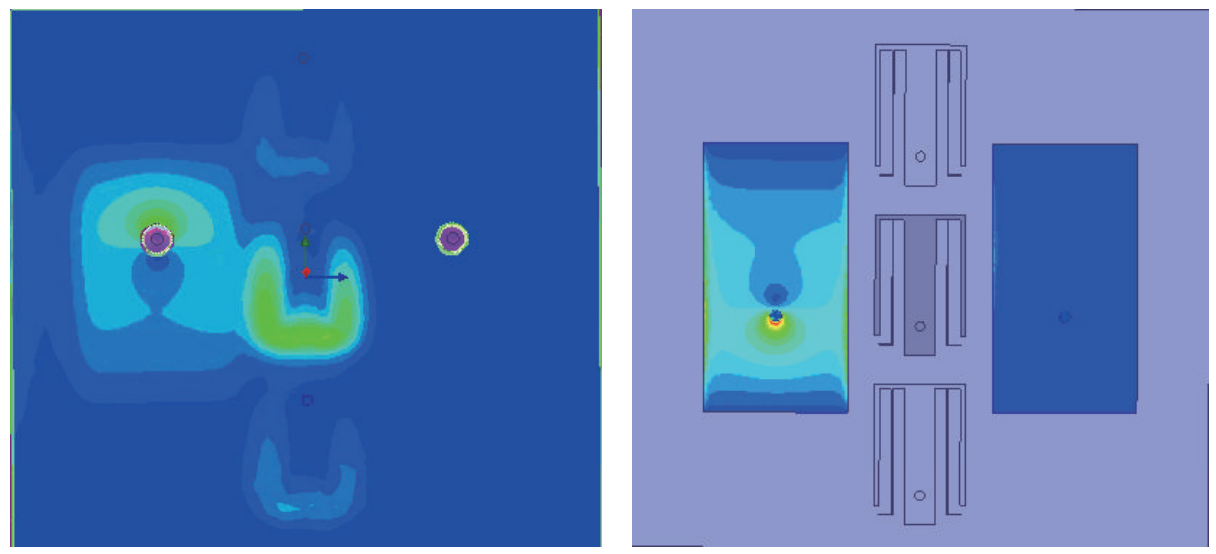

(a) Current density of the proposed array with L-loading E-shaped EBG structure
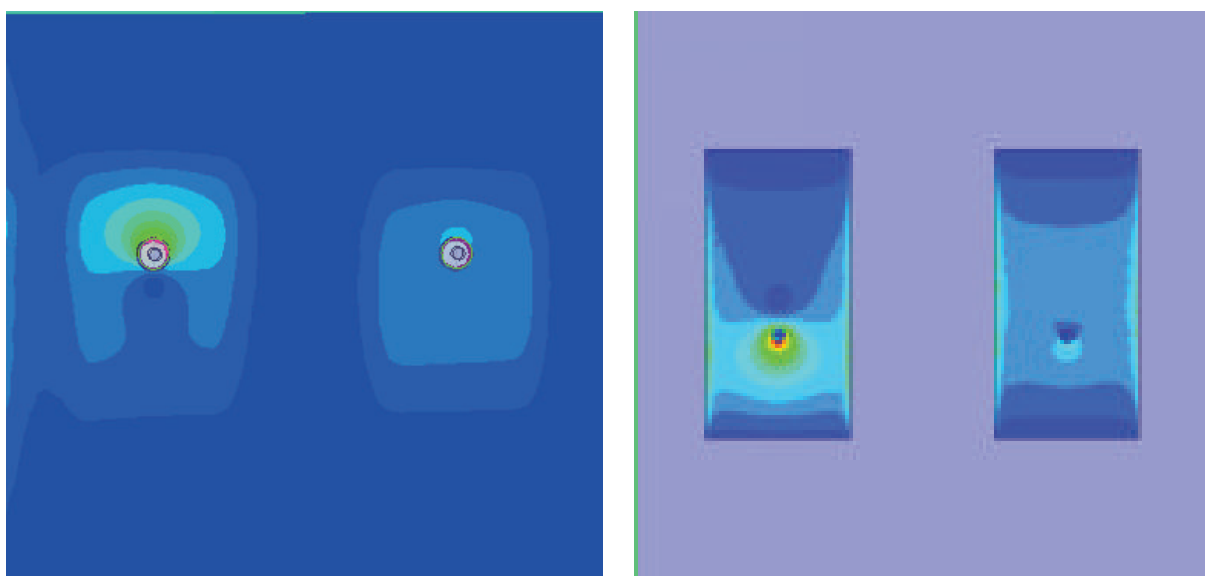

(b) Current density of the proposed array without L-loading E-shaped EBG structure

FIgURE 7: Current distribution of the proposed antenna array.

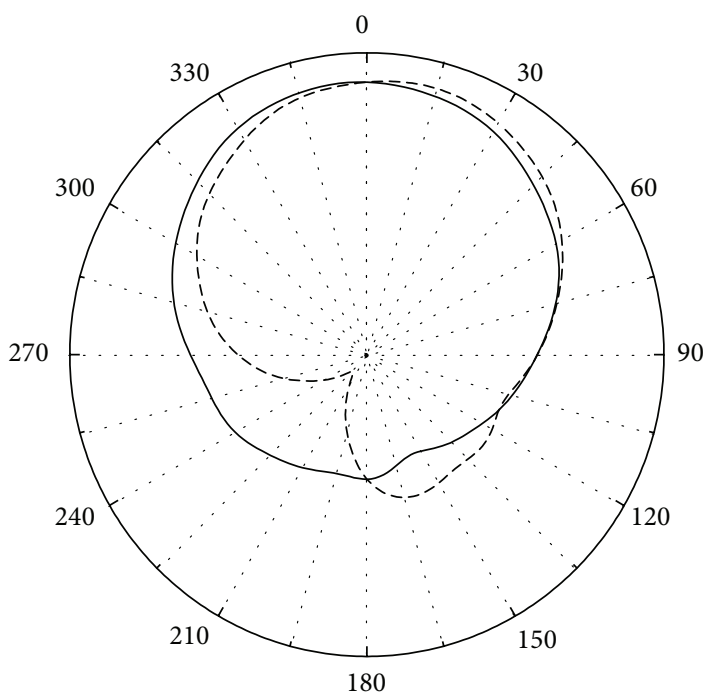

$$
\begin{aligned}
& H \text {-plane } \\
& ---E \text {-plane }
\end{aligned}
$$

FIGURE 8: Radiation patterns of the antenna array with L-loading E-shaped EBG structure. 


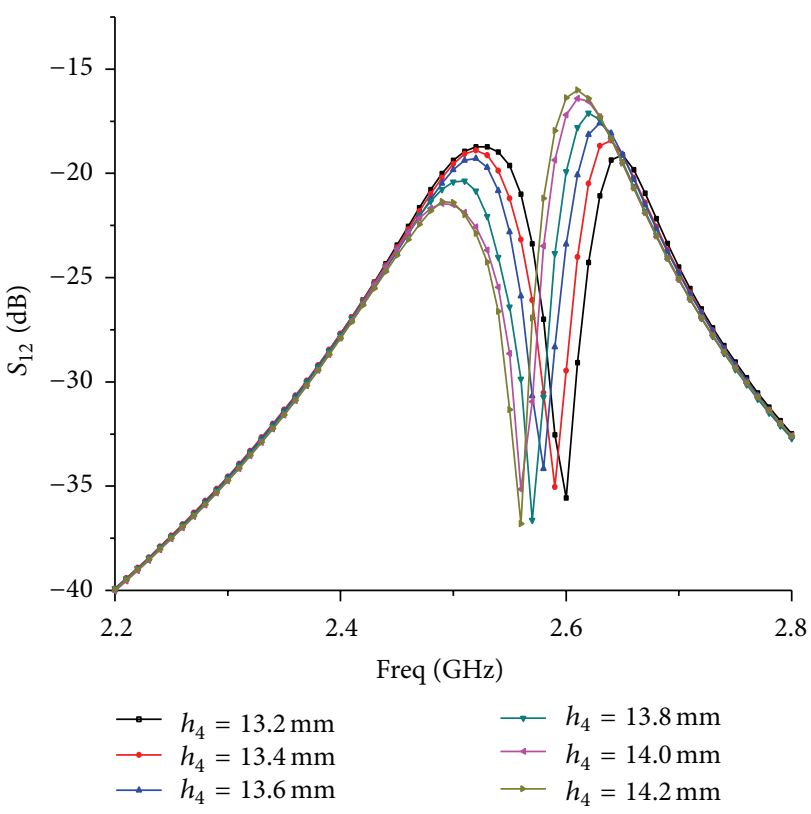

(a)

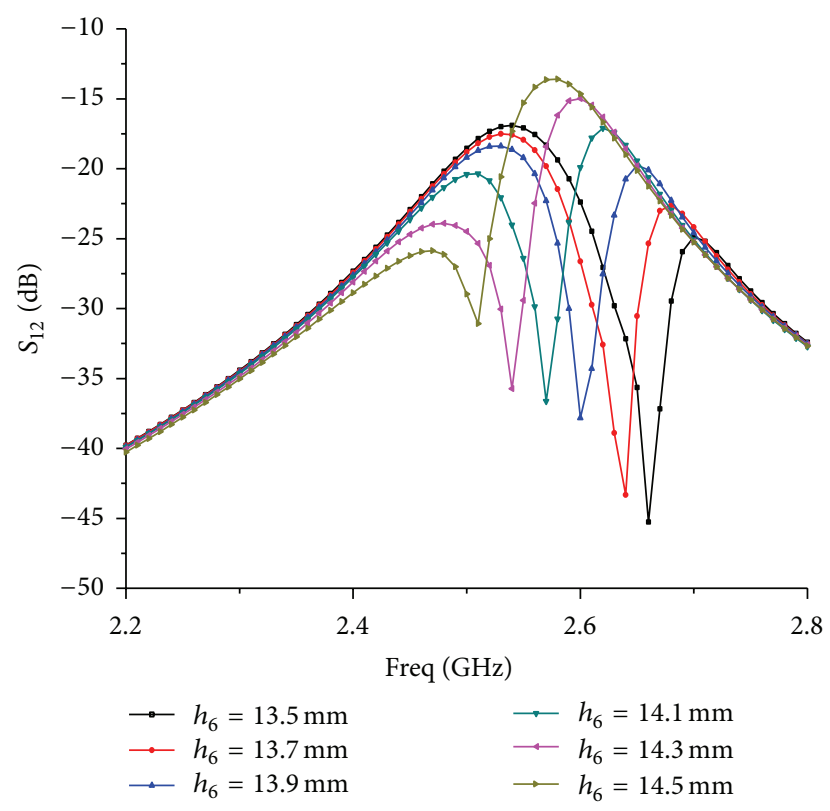

(b)

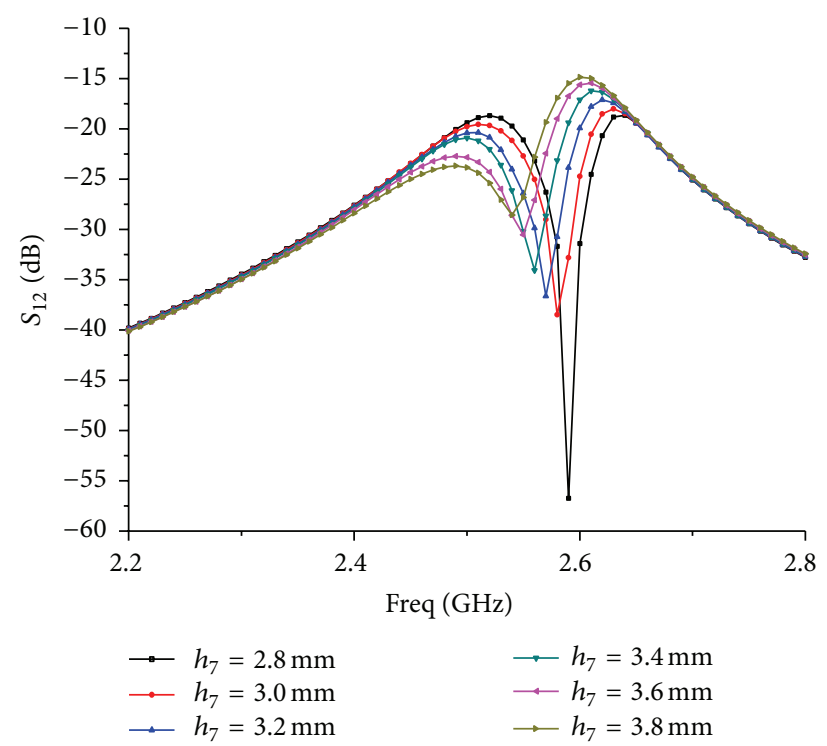

(c)

FIGURE 9: Effects on the mutual coupling reduction of the proposed antenna array with varying parameters.

2.4. Effects on the Key Parameters. In this design, the mutual coupling reduction of the proposed L-loading E-shaped EBG structure is determined by the entire length of L-loading Eshaped EBG cell, which is denoted as $h_{0}=2 \times h_{1}+2 \times h_{4}+$ $2 \times h_{5}+h_{6}+L$. Also, the width of L-stub $h_{2}$ and the width of E-shaped EBG $h_{7}$ have an obvious on-the-antenna resonance frequency. The distance of the antenna array is $30 \mathrm{~mm}$, which is about $0.26 \lambda$ according to its resonance frequency. Here, $h_{4}, h_{6}$, and $h_{7}$ are selected to investigate the mutual coupling reduction of the antenna array and the simulation results are shown in Figure 9.

It can be seen from Figure 9(a) that the center frequency of the decoupling moves to low frequency and the mutual coupling is reduced. When $h_{6}$ and $h_{7}$ are increased, the decoupling center frequencies also shift from high frequency to low frequency, which is shown in Figures 9(b) and 9(c), respectively. Additionally, the decoupling strength becomes weak. Thus, we can adjust the dimensions of the proposed L-loading E-shaped EBG structure to properly select the resonance center frequency and decoupling to make it suitable for practical engineering applications.

\section{Results and Discussions}

In order to get better mutual coupling reduction performance, the proposed L-loading E-shaped EBG structure and 


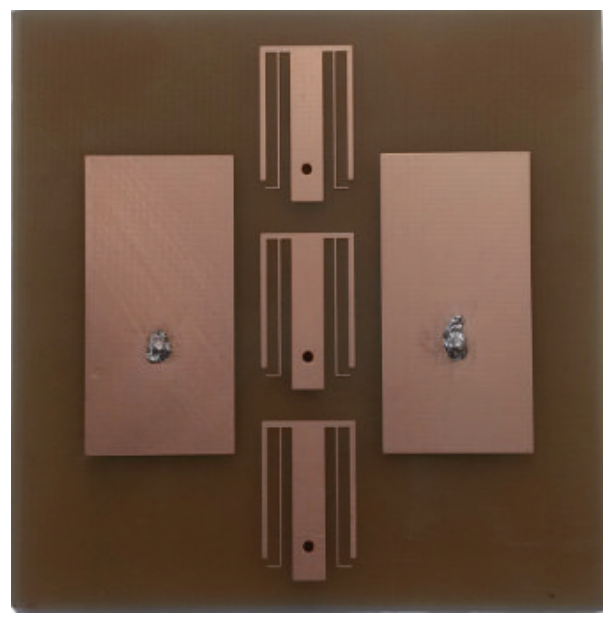

FIGURE 10: Prototype of the fabricated antenna array.

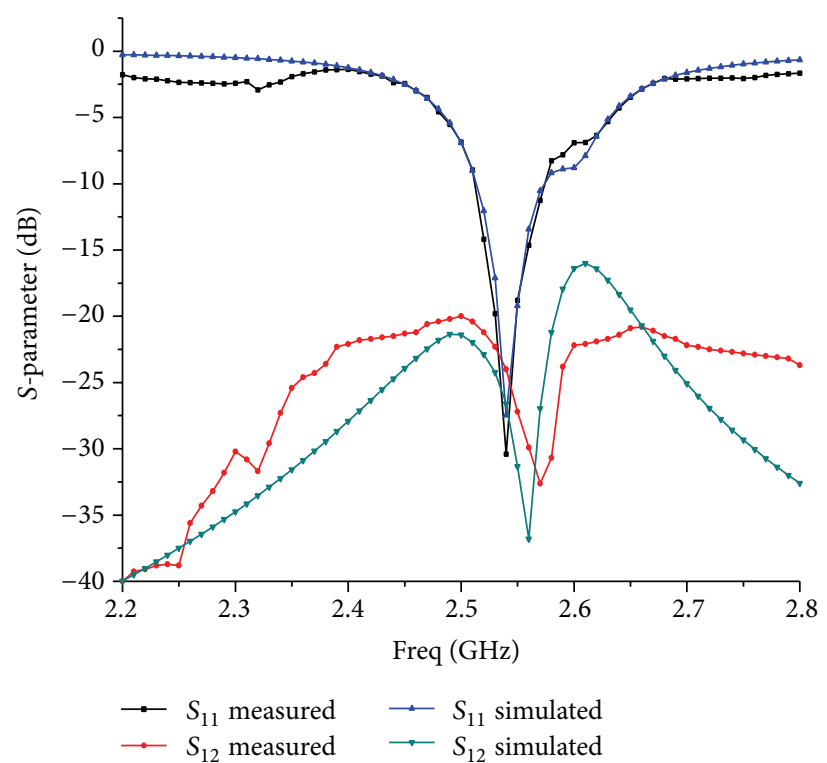

FIGURE 11: Measured $S$-parameter results of the proposed antenna array.

the antenna array are optimized. The parameters of the antenna array are $h_{1}=1.5 \mathrm{~mm}, h_{2}=0.5 \mathrm{~mm}, h_{3}=0.1 \mathrm{~mm}$, $h_{4}=12 \mathrm{~mm}, h_{5}=12.8 \mathrm{~mm}, h_{6}=14 \mathrm{~mm}, h_{7}=3.2 \mathrm{~mm}$, and $q=5 \mathrm{~mm}$. The optimized antenna array is fabricated and measured. The prototype of the fabricated antenna array is shown in Figure 10 and the measured $S$-parameters are given in Figure 11. From the measured results, we can see that the antenna operates at $2.55 \mathrm{GHz}$, while the antenna has an isolation of about $35 \mathrm{~dB}$.

The measured results agree well with the simulation ones, which help to verify the effectiveness of the proposed decoupling structure. However, there is a difference between the measured and simulated $S$-parameters, including $S_{11}$ and $S_{12}$, which may be caused by the fabricated errors. The measured radiation patterns are shown in Figure 12. It can be seen that the measured radiations are similar to the simulated ones.
TABLE 1: Comparison of the sizes and the coupling reductions.

\begin{tabular}{lcc}
\hline References & Size & Coupling reduction \\
\hline$[5]$ & $>50 \mathrm{~mm} \times 60 \mathrm{~mm}$ & $13.54 \mathrm{~dB}$ \\
{$[7]$} & $50 \mathrm{~mm} \times 60 \mathrm{~mm}$ & $8 \mathrm{~dB}$ \\
{$[8]$} & $130 \mathrm{~mm} \times 130 \mathrm{~mm}$ & $10 \mathrm{~dB}$ \\
{$[9]$} & $>84 \mathrm{~mm} \times 72.5 \mathrm{~mm}$ & $17 \mathrm{~dB}$ \\
{$[10]$} & $60 \mathrm{~mm} \times 57 \mathrm{~mm}$ & $42 \mathrm{~dB}$ \\
{$[11]$} & $70 \mathrm{~mm} \times 30 \mathrm{~mm}$ & $27 \mathrm{~dB}$ \\
Proposed & $56 \mathrm{~mm} \times 60 \mathrm{~mm}$ & $26 \mathrm{~dB}$ \\
\hline
\end{tabular}

Table 1 shows the comparisons of the proposed antenna array with previously mutual reduction of antenna arrays with respect to the size and the coupling reduction. 


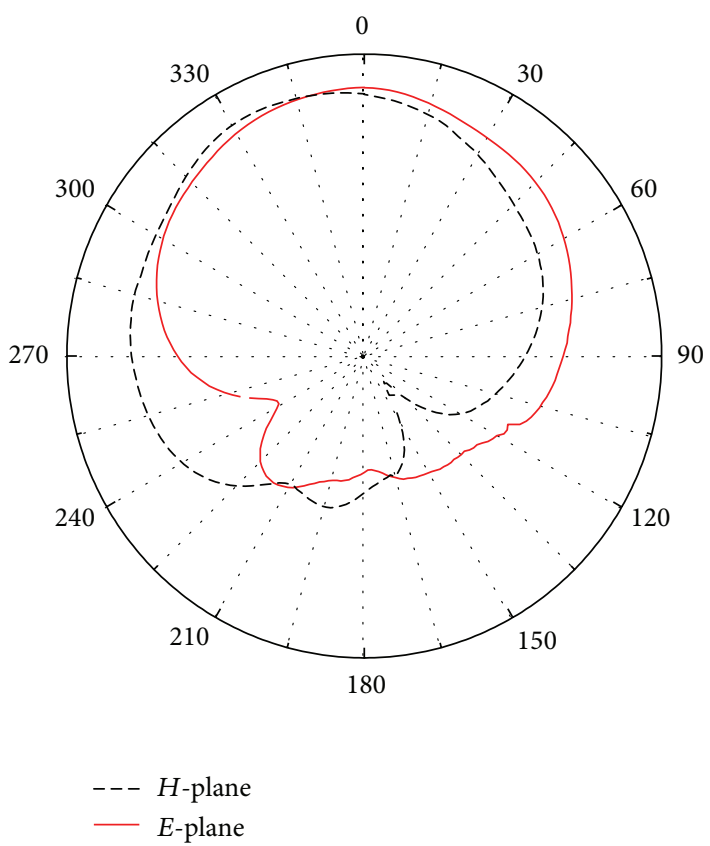

FIGURE 12: Measured radiation patterns of the fabricated antenna array on $E$-plane and $H$-plane.

\section{Conclusion}

An antenna array with periodic L-loading E-shaped EBG structure has been proposed, and its design procedure has been introduced in detail. The performance of the proposed antenna array has been investigated both numerically and experimentally. The mutual coupling reduction has been achieved by using the proposed periodic L-loading E-shaped EBG which has little effects on its radiation patterns. The results demonstrated showed that the proposed antenna array can operate at $2.55 \mathrm{GHz}$ and a $26 \mathrm{~dB}$ coupling reduction has been achieved. Thus, the proposed antenna array is promising for future narrowband wireless communication applications.

\section{Competing Interests}

The authors declare that there are no competing interests regarding the publication of this paper.

\section{Acknowledgments}

This paper was also partially supported by the International Science \& Technology Cooperation Program of China (2014DFR10240) and Projects for the Selected Returned Overseas Chinese Scholars of Heilongjiang Province of China and the Fundamental Research Funds for the Central Universities (HEUCFD1433, HEUCF160815).

\section{References}

[1] Y. Li, W. X. Li, C. Liu, and T. Jiang, "Two UWB-MIMO antennas with high isolation using sleeve coupled stepped impedance resonators," in Proceedings of the IEEE Asia-Pacific
Conference on Antennas and Propagation (APCAP '12), pp. 2122, Singapore, August 2012.

[2] Y. Li, W. Li, and W. Yu, "A multi-band/UWB MIMO/diversity antenna with an enhanced isolation using radial stub loaded resonator," Applied Computational Electromagnetics Society Journal, vol. 28, no. 1, pp. 8-20, 2013.

[3] Q.-R. Zheng, Y.-Q. Fu, and N.-C. Yuan, "A novel compact spiral electromagnetic band-gap (EBG) structure," IEEE Transactions on Antennas and Propagation, vol. 56, no. 6, pp. 1656-1660, 2008.

[4] M. I. Ahmed, A. Sebak, E. A. Abdallah, and H. Elhennawy, "Mutual coupling reduction using defected ground structure (DGS) for array applications," in Proceedings of the 15th International Symposium on Antenna Technology and Applied Electromagnetics (ANTEM '12), pp. 1-5, IEEE, Toulouse, France, June 2012.

[5] B. Mukherjee, S. K. Parui, and S. Das, "Mutual coupling reduction of microstrip antenna arrays using rectangular split ring shaped defected ground structure," in Proceedings of the 2012 International Conference on Communications, Devices and Intelligent Systems (CODIS '12), pp. 202-204, IEEE, Kolkata, India, December 2012.

[6] L. Yang and Z. Feng, "Advanced methods to improve compactness in EBG design and utilization," in Proceedings of the IEEE International Symposium Antenna and Propagation Society (ISAP '04), vol. 4, pp. 3585-3588, June 2004.

[7] F. Yang and Y. Rahmat-Samii, "Microstrip antennas integrated with electromagnetic band-gap (EBG) structures: a low mutual coupling design for array applications," IEEE Transactions on Antennas and Propagation, vol. 51, no. 10, pp. 2936-2946, 2003.

[8] E. Rajo-Iglesias, Ó. Quevedo-Teruel, and L. Inclán-Sánchez, "Mutual coupling reduction in patch antenna arrays by using a planar EBG structure and a multilayer dielectric substrate," IEEE Transactions on Antennas and Propagation, vol. 56, no. 6, pp. 1648-1655, 2008. 
[9] M. T. Islam and M. S. Alam, "Compact EBG structure for alleviating mutual coupling between patch antenna array elements," Progress in Electromagnetics Research, vol. 137, pp. 425-438, 2013.

[10] J.-Y. Lee, S.-H. Kim, and J.-H. Jang, "Reduction of mutual coupling in planar multiple antenna by using 1-D EBG and SRR structures," IEEE Transactions on Antennas and Propagation, vol. 63, no. 9, pp. 4194-4198, 2015.

[11] Z. Qamar, U. Naeem, S. A. Khan, M. Chongcheawchamnan, and M. F. Shafique, "Mutual coupling reduction for highperformance densely packed patch antenna arrays on finite substrate," IEEE Transactions on Antennas and Propagation, vol. 64, no. 5, pp. 1653-1660, 2016.

[12] L. Qiu, F. Zhao, K. Xiao, S.-L. Chai, and J.-J. Mao, "TransmitReceive isolation improvement of antenna arrays by using EBG structures," IEEE Antennas and Wireless Propagation Letters, vol. 11, pp. 93-96, 2012.

[13] M. J. Al-Hasan, T. A. Denidni, and A.-R. Sebak, "A new UC-EBG based-dielectric resonator antenna for millimeterwave applications," in Proceedings of the IEEE International Symposium on Antennas and Propagation (APSURSI '11), pp. 1274-1276, Spokane, Wash, USA, July 2011.

[14] Y. Kong, Y. Li, and W. Yu, "Design of a compact dual-element MIMO-UWB antenna by using slot and stub," in Proceedings of the IEEE Antennas and Propagation (APCAP '15), pp. 101-102, Kuta, Indonesia, July 2015.

[15] K. Yu, Y. Kong, and Y. Li, "A two-element UWB-MIMO antenna with quad narrowband frequency rejection characteristics," in Proceedings of the IEEE/ACES International Conference on Wireless Information Technology and Systems (ICWITS) and Applied Computational Electromagnetics (ACES), pp. 1-2, Honolulu, Hawaii, USA, March 2016.

[16] Q. Li, A. P. Feresidis, M. Mavridou, and P. S. Hall, "Miniaturized double-layer EBG structures for broadband mutual coupling reduction between UWB monopoles," IEEE Transactions on Antennas and Propagation, vol. 63, no. 3, pp. 1168-1171, 2015.

[17] K. Payandehjoo and R. Abhari, "Design of a compact patch antenna backed by a multi-layer EBG structure using multiconductor transmission line modeling," in Proceedings of the IEEE International Symposium on Antennas and Propagation, pp. 1-2, Chicago, Ill, USA, July 2012.

[18] D. Chung, T. H. Kim, C. Ryu, E. Engin, M. Swaminathan, and J. Kim, "Effect of EBG structures for reducing noise in multilayer PCBs for digital systems," in Proceedings of the 14th Topical Meeting on Electrical Performance of Electronic Packaging (EPEP '06), pp. 253-256, IEEE, Scottsdale, Ariz, USA, October 2006.

[19] A. Ramadan, M. Al-Husseini, A. El-Hajj, and K. Y. Kabalan, "Design of a small printed monopole antenna for ultrawideband applications," in Proceedings of the International Conference on Electrical and Electronics Engineering (ELECO '09), pp. II-154II-156, Bursa, Turkey, November 2009.

[20] K. A. Ansal and T. Shanmugantham, "Asymmetric coplanar strip fed antenna with defected ground for wireless application," in Proceedings of the International Conference on Control Communication and Computing (ICCC '13), pp. 249-252, IEEE, Thiruvananthapuram, India, December 2013.

[21] M. Al-Husseini, A. Ramadan, and A. El-Hajj, "Design of a compact and low-cost fractal-based UWB PCB antenna," in Proceedings of the IEEE National Radio Science Conference, pp. 1-8, March 2009.

[22] K. Ikemiya, M. Sakai, and T. Sudo, "Ultra-wideband noise suppression of power supply noise by combining mushroom and planar type EBG structures," in Proceedings of the 3rd IEEE CPMT Symposium Japan (ICSJ '13), pp. 1-4, Kyoto, Japan, November 2013.

[23] Y. S. E. Abdo, M. R. Chaharmir, J. Shaker, and Y. M. M. Antar, "Different techniques to characterize EBG structures for MM wave applications," in Proceedings of the International Conference on Electromagnetics in Advanced Applications (ICEAA '09), pp. 497-500, Torino, Italy, September 2009.

[24] S. Y. Huang and Y. H. Lee, "A novel dual-plane compact electromagnetic band-gap (DPC-EBG) filter design," in Proceedings of the 4th International Conference on Microwave and Millimeter Wave Technology (ICMMT '04), pp. 468-471, August 2004.

[25] A. R. Eskandari, M. N. Moghaddasi, and M. A. Honarvar, "Design of a novel circularly polarized microstrip patch antenna using EBG structure," in Proceedings of the Mediterrannean Microwave Symposium (MMS '09), pp. 1-4, Tangier, Morocco, November 2009. 


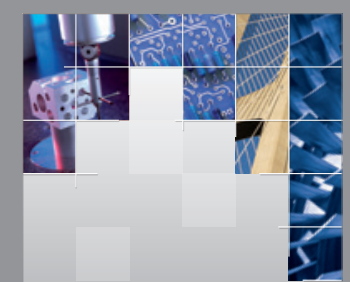

\section{Enfincering}
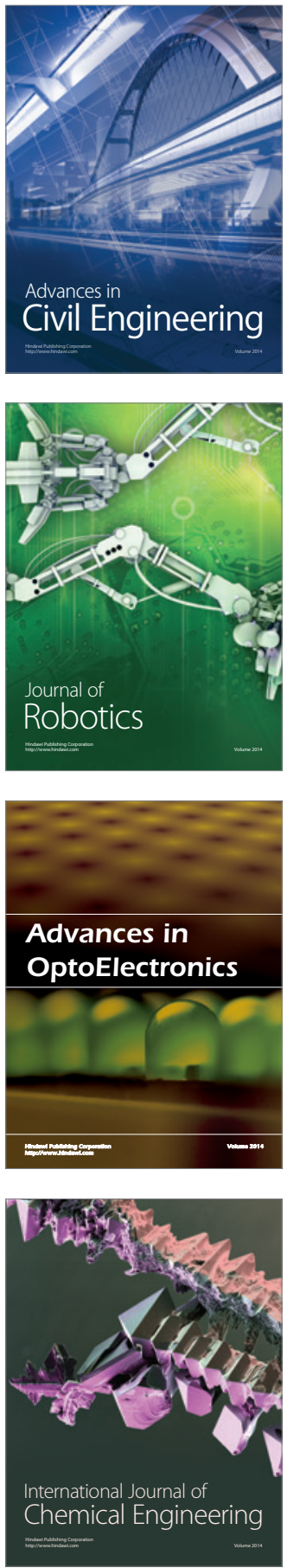

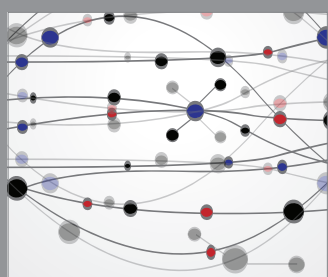

The Scientific World Journal

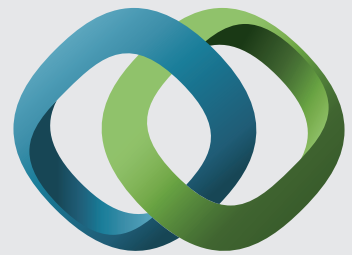

\section{Hindawi}

Submit your manuscripts at

http://www.hindawi.com
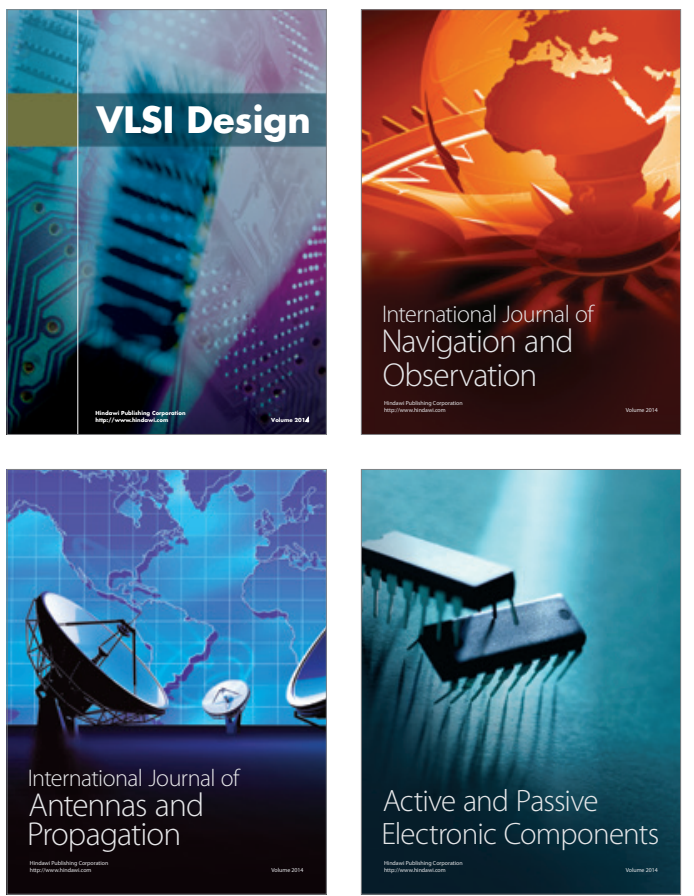
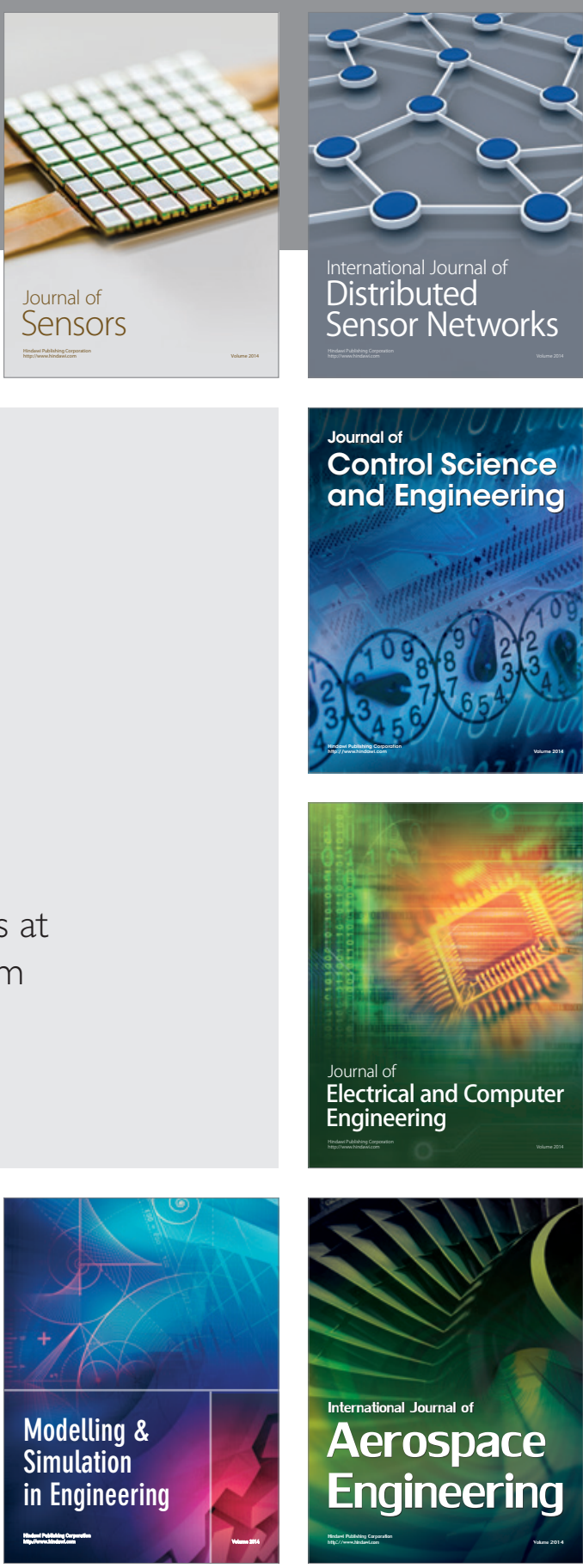

International Journal of

Distributed

Sensor Networks

Journal of

Control Science

and Engineering
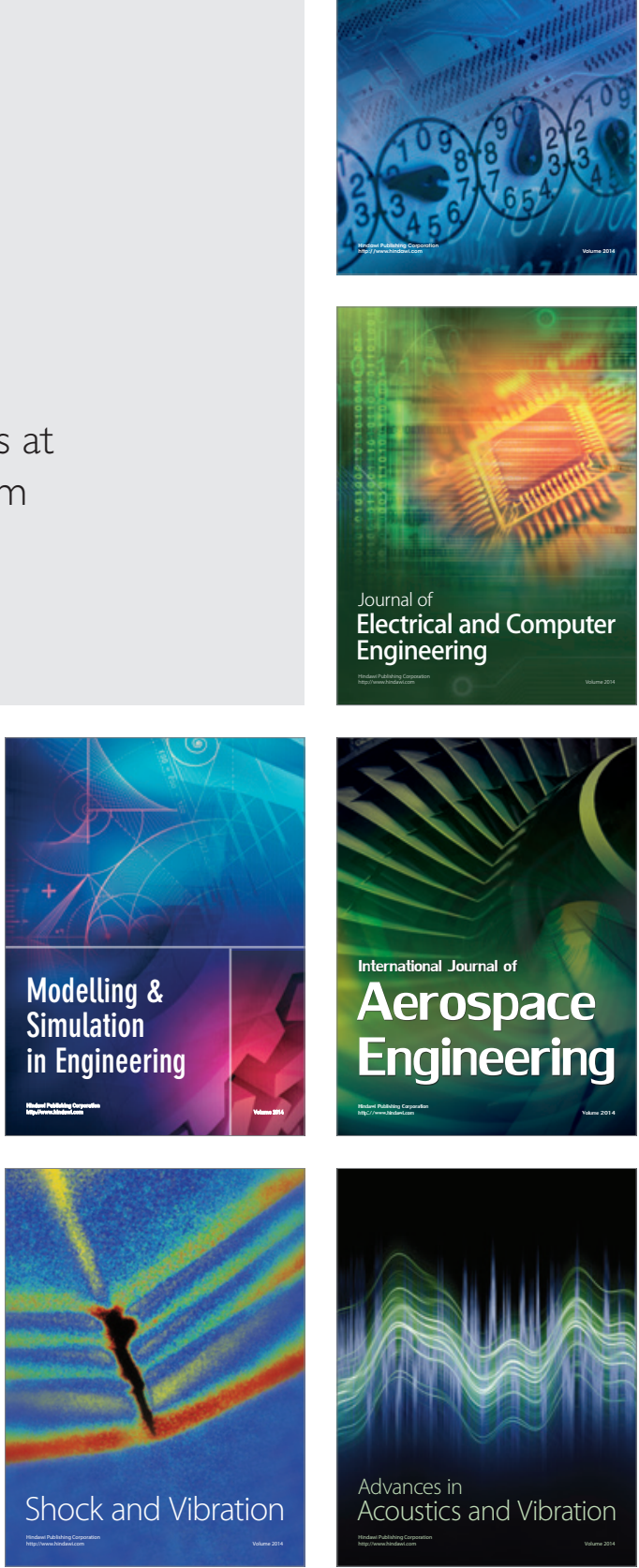